\title{
Review of: "Restricted cement augmentation in unstable geriatric midthoracic fractures treated by long-segmental posterior stabilization leads to a comparable construct stability"
}

\author{
Ayhan Kanat
}

Potential competing interests: The author(s) declared that no potential competing interests exist.

The authors compared the construct stability of long segmental dorsal stabilization in unstable midthoracic osteoporotic fractures with complete pedicle screw cement augmentation (ComPSCA) versus restricted pedicle screw cement augmentation (ResPSCA) of the most cranial and caudal pedicle screws under cyclic loading(1). They used twelve fresh frozen human cadaveric specimens (Th4-Th10) from individuals aged 65 years and older. An unstable Th7 fracture was simulated(1).

There are a number of concerns with this study which include the following:; 1-Understanding of spinal biomechanics and bone growth physiology, along with the development of spinal fixation instrumentation, have allowed exponential growth in spinal surgery(2). The invention of X-ray is an important event in the very early 20th century(3) for development of spinal surgery. . The autors suggest that long segmental posterior stabilization provides a better load distribution compared to short segmental construct. However, controversy still exists regarding the use of posterior fixation by short- or longsegment pedicle screws(4). Instrument- related complications may be seen with shortsegment pedicle screw fixation(4). Alternative procedures supporting the anterior column have been studied, such as vertebroplasty, kyphoplasty, or screw insertion at the fracture level(4).

2-The rules of anatomy and physiology is important issue in spinal pathologies(4). To prevent implant failure, cementing of vertebra in addition to long segment fixation can be used. A good radiological view might not always show that everything is going well(5).

3-Validity in research refers to how accurately a study answers the study question or the strength of the study conclusions(6). Here validity refers to compare the differences in both implant failure rate and peakto-peak amplitudes of movement between the instrumented vertebral bodies between the ResPSCA and ComPSCA group under cyclic loading(1). Thus, the construct stability of long segmental posterior stabilization of an unstable osteoporotic midthoracic fracture using ResPSCA seems to be comparable to ComPSCA(1).

The paper is interesting and add a new informations to current literatüre.

\section{References}

1. Spiegl UJ, Weidling M, Nitsch V, Heilmann R, Heilemann M, Wendler T, et al. Restricted cement augmentation in unstable geriatric midthoracic fractures treated by long-segmental posterior stabilization 
leads to a comparable construct stability. Sci Rep. 2021 Dec;11(1):23816.

2. Kanat A, Yazar U. Spinal surgery and neurosurgeon: quo vadis? J Neurosurg Sci. 2013 Mar;57(1):759.

3. Kanat A, Tsianaka E, Gasenzer E, Drosos E. Some Interesting Points of Competition of X-Ray using during the Greco-Ottoman War in 1897 and Development of Neurosurgical Radiology: A Reminiscence. Turk Neurosurg. :accepted.

4. Ozdemir B, Kanat A, Erturk C, Batcik OE, Balik MS, Yazar U, et al. Restoration of Anterior Vertebral Height by Short-Segment Pedicle Screw Fixation with Screwing of Fractured Vertebra for the Treatment of Unstable Thoracolumbar Fractures. World Neurosurg. 2017 Mar;99:e39.

5. Kanat A, Ozdemir B. In Reply to the Letter to the Editor regarding "Restoration of Anterior Vertebral Height by Short-Segment Pedicle Screw Fixation with Screwing of Fractured Vertebra for the Treatment of Unstable Thoracolumbar Fractures." World Neurosurg [Internet]. 2017 May;101:793. Available from: http://www.sciencedirect.com/science/article/pii/S1878875017302292

6. Ozdemir B, Kanat A, Durmaz S, Ersegun Batcik O, Gundogdu H. Introducing a new possible predisposing risk factor for odontoid type 2 fractures after cervical trauma; Ponticulus posticus anomaly of C1 vertebra. J Clin Neurosci Off J Neurosurg Soc Australas. 2021 Nov; 